\title{
Adaptive estimation of phoneme boundaries and selective adaptation for speech
}

\author{
ISRAEL RAZ and FREDERIC L. WIGHTMAN \\ Northwestern University, Evanston, Illinois
}

\begin{abstract}
Previous studies have estimated the boundary between two phoneme categories from identification data. This procedure is time consuming, especially in studies of selective adaptation, in which it is necessary to test identification twice, before and during adaptation. We adapted a simple up-down adaptive procedure to estimate the phoneme boundary. The stimulus to be presented on a given trial is determined from the subjects' past responses. Two stimulus continua were synthesized: a voicing continuum (13 stimuli changing from $/ \mathrm{ba} /$ to $/ \mathrm{pa} / /$ and a place continuum (13 stimuli changing from $/ \mathrm{ba} /$ to $/ \mathrm{da} /$ and $/ \mathrm{ga} /$ ). Twenty-two normal listeners were given an identification test with each set of stimuli. A logistic curve was fit to the obtained identification function from each subject. Next, phoneme boundaries were directly estimated with the adaptive procedure. The $50 \%$ points on the curves from the identification procedure were highly correlated with those estimated by the adaptive procedure. Phoneme boundaries were also measured before and during selective adaptation (using all end-point stimuli as adaptors in separate sessions). Boundary shifts were obtained in the expected directions and magnitudes. The adaptive procedure is faster than the identification test and exhibits high test-retest reliability.
\end{abstract}

Studies of speech perception are often interested in estimating the perceptual boundary between two phoneme categories. Phoneme boundaries (e.g., Ganong \& Zatorre, 1980) have usually been estimated by analyzing the results of identification tests. In these tests, members of a continuum of stimuli are presented for identification in random order. The identification functions describing the labeling responses express percent identification for each phoneme category as a function of the stimulus value along the continuum. The phoneme boundary (i.e., the stimulus value that is assigned to either category $50 \%$ of the time) is determined by means of interpolation or curve-fitting procedures.

Although in some instances, such as in studies on categorical perception, the whole identification function is of interest, in other investigations only an estimate of the phoneme boundary is of interest. In the latter case, the practice of obtaining full identification functions is time consuming and superfluous. Ganong and Zatorre (1980) addressed this issue and showed that equivalent estimates of phoneme boundaries may be obtained with different procedures, all requiring less testing time than the identification test. Various adaptive algorithms have been used to estimate phoneme boundaries in adults (Summerfield \& Haggard, 1977), children (Elliott, Longinotti,

This research was supported bv Grant 5T32NS07108 from NINCDS. The authors' mailing address is: Auditory Research Laboratory, Program in Audiology and Hearing Impairment, Northwestern University, 2299 Sheridan Road, Evanston, IL 60201 .
Meyer, Raz, \& Zucker, 1981), and infants (Aslin, Pisoni, Hennessy, \& Perey, 1981).

The time factor involved in the traditional method of estimating phoneme boundaries becomes most crucial in studies of selective adaptation for speech. This test necessitates the repeated presentation of a member of a stimulus continuum which alters the identification of some stimuli along the continuum. This effect, first described by Eimas and Corbit (1973), has usually been expressed as a shift in the location of the boundary toward the category of the adapting stimulus. The procedure involves two stages: First, a baseline (preadaptation) identification function is obtained, as described above, and the phoneme boundary is calculated. Next, a series of adaptation sessions is run. Every adaptation session retests the identification function. However, the presentation of stimuli for identification is interrupted during presentation of the adapting stimulus. The amount of adaptation on each trial and the frequency of the interruption range from 10 repetitions every item (Miller, Connine, Schermer, \& Kluender, 1983) to 180 or more repetitions every 11 items (e.g., Cole, Cooper, Singer, \& Allard, 1975). Following each adaptation trial, a new identification function is derived and the boundary is compared with the preadaptation boundary. Many investigators have reported adaptation sessions to last up to $2 \mathrm{~h}$. The present study investigates the use of a simple up-down adaptive procedure (Levitt, 1971) to estimate the boundary between two phoneme categories and the shift in the boundary location resulting from the selective adaptation effect.

Two experiments will be reported. Experiment 1 
tested the hypothesis that direct estimates of phoneme boundaries obtained with a simple up-down adaptive procedure agree with those derived from complete identification functions. Experiment 2 tested the hypothesis that adaptive estimates of the shift in phoneme boundaries following selective adaptation correspond in terms of magnitude and direction to previous reports employing traditional testing procedures. All tests were conducted with two stimulus sets: a voicing $(/ \mathrm{ba} /-/ \mathrm{pa} /)$ continuum and a place (/ba/-/da/-/ga/) continuum.

\section{EXPERIMENT 1: BOUNDARY ESTIMATION}

Before the simple up-down adaptive procedure could be used to measure a change in phoneme boundary following adaptation, it was necessary to determine whether the boundaries estimated with this method agreed with those derived from identification functions.

\section{Method}

Subjects. Twenty-two normal-hearing adults between the ages of 17 and 24 years participated in the experiments. The subjects were tested individually.

Stimuli. All stimuli were synthesized with an implementation (Kewley-Port, 1978) of a cascade terminal-analog speech synthesizer (Klatt, 1980). Stimuli were generated off-line and stored on magnetic disk. They were played at a rate of $10 \mathrm{kHz}$ through a 14bit $D / A$ converter, low-pass filtered at $4200 \mathrm{~Hz}$. Two stimulus continua were generated; a voicing continuum (13 stimuli changing from $/ \mathrm{ba} /$ to $/ \mathrm{pa} /$ ) and a place continuum (13 stimuli changing from $/ \mathrm{ba} /$ to $/ \mathrm{da} / \mathrm{and} / \mathrm{ga} /$ ). All stimuli were $300 \mathrm{msec}$ in duration and had five formants, with initial 40-msec transitions on the first three formants and a final, fixed location corresponding to the vowel [a].

In the voicing continuum, the fixed formant frequencies (and bandwidths) for the five formants were: $700 \mathrm{~Hz}(90 \mathrm{~Hz}), 1200 \mathrm{~Hz}$ $(90 \mathrm{~Hz}), 2600 \mathrm{~Hz}(130 \mathrm{~Hz}), 3300 \mathrm{~Hz}(400 \mathrm{~Hz})$, and $3700 \mathrm{~Hz}$ $(500 \mathrm{~Hz})$. Starting frequencies of the transitions to the first three formants were 400,1000 , and $2400 \mathrm{~Hz}$. Voice onset time (VOT) values increased in 5-msec steps between stimulus 1 and 11 (VOT values of 0 and $50 \mathrm{msec}$, respectively) and were 60 and $70 \mathrm{msec}$ for stimuli 12 and 13 , respectively. VOT was controlled by preceding the onset of voicing with a 5 -msec noise burst followed by aspiration equal in duration to the VOT selected for each stimulus. For stimulus 1 , voicing onset coincided with the release of the noise burst. Voicing amplitude decreased linearly from full amplitude to full attenuation over the last $100 \mathrm{msec}$ of each syllable. Fundamental frequency rose from 120 to $125 \mathrm{~Hz}$ during the first $50 \mathrm{msec}$ of the syllable and then fell linearly to $100 \mathrm{~Hz}$ over the remaining steady-state portion of the vowel.

In the place continuum, the fixed frequencies (and bandwidths) for the five formants were $720 \mathrm{~Hz}(50 \mathrm{~Hz}), 1240 \mathrm{~Hz}(80 \mathrm{~Hz})$ $2500 \mathrm{~Hz}(120 \mathrm{~Hz}), 3600 \mathrm{~Hz}(250 \mathrm{~Hz})$, and $4500 \mathrm{~Hz}(300 \mathrm{~Hz})$. The stimuli were constructed such that items 1,7 , and 13 were perceived as the best exemplars of $/ \mathrm{ba} /, / \mathrm{da} /$, and $/ \mathrm{ga} /$, respectively. Starting frequencies for the second and third formant transitions were 942 and $1904 \mathrm{~Hz}$ for stimulus 1,1700 and $2791 \mathrm{~Hz}$ for stimulus 7 , and 1650 and $1904 \mathrm{~Hz}$ for stimulus 13 , respectively. Starting frequencies for the second and third formant transitions for all other stimuli were interpolated to change in equal steps on a logfrequency scale. Starting frequency of the transitions to the first formant was $200 \mathrm{~Hz}$ for all stimuli. Voicing amplitude decreased linearly over a range of $40 \mathrm{~dB}$ during the last $50 \mathrm{msec}$ of each syl- lable. Fundamental frequency rose linearly from 103 to $125 \mathrm{~Hz}$ within the first $40 \mathrm{msec}$ of voicing, dropped to $100 \mathrm{~Hz}$ within the next $180 \mathrm{msec}$, and then dropped to $50 \mathrm{~Hz}$ during the final $80 \mathrm{msec}$ of each syllable.

Procedure. All subjects participated in two experimental tasks: identification and adaptive boundary estimation. In the identification task, all members of a stimulus continuum were presented 12 times in random order. Following each presentation, the listeners pressed a response button labeled with the phoneme category to which they assigned each stimulus $(/ \mathrm{ba} /$ or $/ \mathrm{pa} /$ for the voicing continuum, and $/ \mathrm{ba} / \mathrm{da} /$ or $/ \mathrm{ga} /$ for the place continuum). Responses to the first two presentations of each stimulus were discarded, and those to the last 10 presentations were analyzed in terms of frequency of assignment of every stimulus to each phoneme category.

The second task involved a direct estimate of the boundary between two preselected phoneme categories using a simple up-down adaptive procedure. With this method, the stimulus to be presented on a given trial is determined by the listener's last response. For example, in estimating the $/ \mathrm{ba} /-/ \mathrm{da} /$ boundary, stimulus 3 was presented on the first trial. If it was labeled "ba," the next trial presented stimulus 4 . If the response to stimulus 3 was "da," the next trial presented stimulus 2 . The procedure converged on the phoneme boundary, increasing stimulus value following a "ba" response and decreasing stimulus value following a "da" response. Testing was terminated when 10 reversals in the direction of stimulus change were obtained. The boundary was determined by averaging stimulus values at the last eight reversal points. The same procedure was used to estimate the $/ \mathrm{da} /-/ \mathrm{ga} /$ and $/ \mathrm{ba} /-$ /pa/ boundaries.

All subjects participated in a practice session followed by two experimental sessions. In each experimental session, two identification functions were obtained, one for the voicing and one for the place continuum. Then two adaptive estimates of all three phoneme boundaries were obtained. All tests within an experimental session were administered in random order. The identification responses obtained in both experimental sessions for each continuum were averaged to produce the final identification curve for every subject. The adaptive estimates of all phoneme boundaries in each session are based on the average of two independent runs.

Stimulus synthesis, subject-paced test administration, and response collection were controlled by a DEC PDP-11/40 minicomputer. Stimuli were presented monaurally via TDH-49 earphones mounted in circumaural cushions at an rms level of $85 \mathrm{~dB}$ SPL for a continuous synthetic vowel [a].

\section{Results}

The major goal of this experiment was to assess the validity of the adaptive phoneme boundary estimates in terms of their correspondence to the boundary values derived from identification functions. In addition, we were interested in evaluating the reliability of the adaptive procedure in this particular application.

A logistic curve (Bush, 1963) was fit to the identification functions obtained from each subject. The phoneme boundary was taken as the interpolated stimulus value that corresponded to a $50 \%$ response level on that curve. Table 1 shows group mean, standard deviation, minimum and maximum stimulus values for all phoneme boundaries as obtained by (a) identification functions, (b) adaptive estimation, and (c) replication of the adaptive procedure in a separate session. Values in (b) and (c) are based on the average of two runs per session.

Examination of Table 1 suggests a remarkably 
Table 1

Mean, Standard Deviation (SD), and Minimum and Maximum Stimulus Values for Three Phonetic Boundaries, Interpolated from Curves Fitted to the Identification Functions (Identification) and Estimated (Up-Down) and Retested with the Adaptive Procedure

\begin{tabular}{|c|c|c|c|c|c|}
\hline Boundary & Test & Mean & SD & Minimum & Maximum \\
\hline ba-pa & $\begin{array}{l}\text { Identification } \\
\text { Up-Down } \\
\text { Retest }\end{array}$ & $\begin{array}{l}6.138 \\
6.196 \\
5.621\end{array}$ & $\begin{array}{l}.452 \\
.918 \\
.946\end{array}$ & $\begin{array}{l}5.290 \\
3.500 \\
3.167\end{array}$ & $\begin{array}{l}7.053 \\
7.500 \\
7.167\end{array}$ \\
\hline ba-da & $\begin{array}{l}\text { Identification } \\
\text { Up-Down } \\
\text { Retest }\end{array}$ & $\begin{array}{l}4.852 \\
4.834 \\
5.057\end{array}$ & $\begin{array}{l}.360 \\
.701 \\
.636\end{array}$ & $\begin{array}{l}3.951 \\
3.167 \\
3.667\end{array}$ & $\begin{array}{l}5.485 \\
5.750 \\
6.000\end{array}$ \\
\hline da-ga & $\begin{array}{l}\text { Identification } \\
\text { Up-Down } \\
\text { Retest }\end{array}$ & $\begin{array}{r}10.008 \\
9.955 \\
9.807\end{array}$ & $\begin{array}{l}.591 \\
.705 \\
.762\end{array}$ & $\begin{array}{l}8.855 \\
8.667 \\
8.250\end{array}$ & $\begin{array}{l}11.307 \\
10.667 \\
10.667\end{array}$ \\
\hline
\end{tabular}

Note $-n=22$.

Table 2

Pearson Product-Moment Correlations Between Adaptive Estimates and Their Replications (Up-Down/Retest) and Between Adaptive and Fitted Estimates (Up-Down/ldentification) for Three Phoneme-Boundaries

\begin{tabular}{ccc}
\hline Boundary & $\begin{array}{c}\text { Up-Down/ } \\
\text { Retest }\end{array}$ & $\begin{array}{c}\text { Up-Down/ } \\
\text { Identification }\end{array}$ \\
\hline ba-pa & .7403 & .5261 \\
ba-da & .7652 & .6021 \\
da-ga & .8875 & .7570 \\
\hline
\end{tabular}

Note- $n=22, p<.006$.

close agreement among all phoneme-boundary estimates for both the voicing and place continua. In fact, all mean values within a phoneme-category contrast are within less than one stimulus value apart. The observed strong relation is supported by the Pearson product moment correlations among the various estimates of each phoneme boundary shown in Table 2. Thus, we conclude that the simple updown adaptive method may be reliably used to estimate the boundary between two phoneme categories.

\section{EXPERIMENT 2: SELECTIVE ADAPTATION}

This experiment addressed the main goal of the present study. The principle of simple up-down adaptive tracking was used to estimate changes in phoneme boundaries following adaptation. Subjects and stimuli were the same as in the first experiment. All the data for Experiment 1 were collected prior to adaptation.

\section{Method}

Each subject participated in six sessions of approximately 30 min each, conducted on separate days. Every session included a baseline adaptive estimate of a particular phoneme boundary followed by an adaptation test. The adaptation test was identical to the baseline boundary estimation, except that it was interspersed with an adapting syllable. The adaptor was presented 200 times at the beginning of the test and 100 times following each block of eight test stimuli, with an interadaptor interval of $300 \mathrm{msec}$. The first test stimulus in each block was presented $2 \mathrm{sec}$ following the termination of the last adaptor. Within each block, or adaptation trial, stimulus values to be presented were determined by the simple up-down rules described in the Procedure section for Experiment 1 . Testing was terminated when 10 reversals in the direction of stimulus change were obtained across all adaptation trials. The boundary was determined by averaging stimulus values at the last eight reversal points. The amount of adaptation was calculated by subtracting the boundary value estimated during the adaptation test from that obtained in the baseline condition. Stimuli 1 and 13 of the voicing continuum served as adaptors for the $/ \mathrm{ba} /-/ \mathrm{pa} /$ boundary, and stimuli 1 and 7 and stimuli 7 and 13 of the place continuum served as adaptors for the $/ \mathrm{ba} /-/ \mathrm{da} /$ and $/ \mathrm{da} /-/ \mathrm{ga} /$ boundaries, respectively, all in separate sessions.

\section{Results}

The amount of shift (in stimulus value) for all phoneme boundaries following adaptation is shown in Table 3. Positive mean values indicate a shift toward larger stimulus values, whereas negative mean values indicate a shift toward smaller stimulus values

Table 3

Mean, Standard Deviation (SD), and Maximum and Minimum Stimulus Values for the Amount of Shift in Three Boundaries After Adaptation with Various Stimuli

\begin{tabular}{|c|c|c|c|c|c|}
\hline Boundary & Adaptor (Stimulus No.) & Mean & SD & Minimum & Maximum \\
\hline ba-pa & $\begin{array}{l}\text { ba (1) } \\
\text { pa (13) }\end{array}$ & $\begin{array}{r}-1.148 \\
2.337\end{array}$ & $\begin{array}{r}.599 \\
1.172\end{array}$ & $\begin{array}{r}-.250 \\
.625\end{array}$ & $\begin{array}{r}-2.190 \\
5.375\end{array}$ \\
\hline ba-da & $\begin{array}{ll}\text { ba } & (1) \\
\text { da } & (7)\end{array}$ & $\begin{array}{r}-1.027 \\
1.051\end{array}$ & $\begin{array}{l}.512 \\
.329\end{array}$ & $\begin{array}{r}-.167 \\
.333\end{array}$ & $\begin{array}{r}-2.333 \\
1.667\end{array}$ \\
\hline da-ga & $\begin{array}{l}\mathrm{da}(7) \\
\text { ga (13) }\end{array}$ & $\begin{array}{r}-1.385 \\
.954\end{array}$ & $\begin{array}{l}.525 \\
.645\end{array}$ & $\begin{array}{r}-.333 \\
.125\end{array}$ & $\begin{array}{r}-2.500 \\
2.250\end{array}$ \\
\hline
\end{tabular}

Note $\rightarrow n=22$. 
along the respective continuum. Examination of $\mathrm{Ta}$ ble 3 suggests that our procedure consistently shows the expected adaptation effects for all adaptorboundary combinations. The shifts in the boundary locations are always toward the adapting stimulus. Furthermore, as noted by Eimas, Cooper, and Corbit (1973), our voicing data show that a voiceless adaptor has a considerably larger effect on the voicedvoiceless boundary than does a voiced adaptor.

\section{SUMMARY}

The results of the present study suggest that the simple up-down adaptive procedure can be used to directly estimate the boundary location between two phoneme-categories. We have also shown that this procedure can be applied to measure selective adaptation to speech in sessions lasting about $10 \mathrm{~min}$. The generality of our findings is supported by data obtained with three phoneme boundaries and two different stimulus continua. Although we measured selective adaptation effects at the phoneme boundary, within-category effects could be estimated with a transformed up-down method (Levitt, 1971) be converging on different points on the psychometric curve.

\section{REFERENCES}

Aslin. R. N., Pisoni, D. B., Hennessy, B. L., \& Perey, A. J. (1981). Discrimination of voice onset time by human infants: Findings and implications for the effects of early experience. Child Development, 52, 1135-1145.
Bush, R. R. (1963). Estimation and evaluation. In R. D. Luce, R. R. Bush, \& E. Galanter (Eds.), Handbook of mathematical psychology (pp. 429-469). New York: Wiley.

Cole, R. A., Cooper, W. E., Singer, J., \& Allard, F. (1975). Selective adaptation of English consonants using real speech. Perception \& Psychophysics, 18, 227-244.

Eimas, P. D., Cooper, W. E., \& Corbit, J. D. (1973). Some properties of linguistic feature detectors. Perception \& Psychophysics, 13, 247-252.

Eimas, P. D., \& Conbit, J. D. (1973). Selective adaptation of linguistic feature detectors. Cognitive Psychology, 4, 99-109.

Elliott, L. L., Longinotti, C., Meyer, D., RAz, I., \& Zucker, K. (1981). Developmental differences in identifying and discriminating CV syllables. Journal of the Acoustical Society of of America, 70, 669-677.

Ganong III, W. F., \& Zatorre, R. J. (1980). Measuring phoneme boundaries four ways. Journal of the Acoustical Society of America, 68, 431-439.

KEWLEY-PoRT, D. (1978). KLTEXC: Executive program to implement the KLATT software speech synthesizer (Research in Speech Perception Progress Report No. 4, pp. 235-246). Bloomington: Indiana University, Department of Psychology.

KLATT, D. H. (1980). Software for a cascade/parallel formant synthesizer. Journal of the Acoustical Society of America, 67, 971-995.

LevitT, H. (1971). Transformed up-down methods in psychoacoustics. Journal of the Acoustical Society of America, 49, 467-477.

Miller, J. L., Connine, C. M., Schermer, T. M., \& Kluender, K. R. (1983). A possible auditory basis for internal structure of phonetic categories. Journal of the Acoustical Society of America, 73, 2124-2133.

Summerfield, Q., \& HAggard, M. (1977). On the dissociation of spectral and temporal cues to the voicing distinction in initial stop consonants. Journal of the Acoustical Society of America, 62, 435-448.

(Manuscript received December 30, 1983; revision accepted for publication May 25, 1984.) 